\title{
Relationships between gait properties on soft surfaces, physical function, and fall risk for the elderly
}

\author{
Shinichi Demura ${ }^{1}$, Sohee Shin ${ }^{2}$, Shinji Takahashi ${ }^{3}$, Shunsuke Yamaji ${ }^{4^{*}}$ \\ ${ }^{1}$ Graduate School of Natural Science and Technology, Kanazawa University, Kanazawa, Japan \\ ${ }^{2}$ School of Medicine, Gifu University, Gifu, Japan \\ ${ }^{3}$ Teikyo Heisei University, Chiba, Japan \\ ${ }^{4}$ Faculty of Medical Sciences, Morphological and Physiological Sciences, Sports Medicine, University of Fukui, Fukui, Japan; \\ ${ }^{*}$ Corresponding Author: yamaji@u-fukui.ac.jp
}

Received 5 December 2012; revised 20 January 2013; accepted 27 January 2013

Copyright (C) 2013 Shinichi Demura et al. This is an open access article distributed under the Creative Commons Attribution License, which permits unrestricted use, distribution, and reproduction in any medium, provided the original work is properly cited.

\section{ABSTRACT}

The plantar aspect change caused by contact with soft surfaces creates and unstable gait and increases the risk of falling, especially in the elderly. This study aimed to analyze gait property by three-dimensional motion analysis on soft and normal surfaces and to clarify the relationship with physical function and fall risk. Twenty-four older people aged 65 - 88 years old and living independently without any assistive device (7 men, 17 women) performed $5 \mathrm{~m}$ of walking with own maximal speed on normal and soft surface walkways. The soft surface walkway used was a low rebound urethane foam mattress. The three-dimensional kinematic gait analysis by sixteen anatomic points was used to evaluate gait property on both walkways. The gait property on soft surfaces tended to be swinging up and down in each joint and to largely lean left and right as compared with the normal surface. Moreover, it tended to decrease in a step length and to increase in a step width. All gait parameters on soft surfaces correlated significantly with functional reach. On the other hand, that on normal surface correlated significantly with leg strength. Gait properties on soft surfaces which changes in plantar aspect during foot contact differs from those on normal surfaces. Walking on soft surfaces may cause an unanticipated inverted pendulum sway supporting a foot contact point because of the disturbance by a sagging walkway; in short, requiring more effort to keep a body balanced. In conclusion, gait on the soft surfaces requires balance ability (functional reach) rather than leg strength.

Keywords: Three-Dimensional Kinematic Analysis; Leg Strength; Balance

\section{INTRODUCTION}

Prolongation of independent life for the elderly and control of the marked increased rate of medical expenses are key tasks in Japan, which has become a super aging society. Mobility is one of the most basic skills necessary to keep an independent daily life. Their falls bring about serious problems related to the decline of quality of life, such as the bedridden state caused by bone fractures, and the decline of activity range and volume due to the fear of falling. It was reported that more than one third of the elderly over 70 years of age living independently in communities experience a fall at least once a year, and their fall occur chiefly during walking or transfer movement [1].

A fall is the result of exceeding the limit of one's own postural control from any cause. Age-related decline in the physical functioning of visual, locomotion, and nervous system makes stability during walking difficult. However, a fall during walking rarely occurs without some sort of trigger, except for those who fall due to dizziness or syncopy. Most falls involve a trigger such as a misstep or slip. The risk of falling increases when a person lacks the ability to adapt to surface environment changes (e.g. tilt, difference in floor height, slipperiness, and hardness change) [2-4].

Many mobility tests that evaluate fall-related physical fitness have been proposed in the previous studies: $10-\mathrm{m}$ 
Walking Test [5], Figure Eight Track Walking Test [6], Timed Up and Go Test [7], and Tandem Gait Test [8]. These tests are useful to evaluate the independence of daily living. However, mobility on stationary surfaces may not reflect the ability to avoid a fall, because the fall risk relates to the adaptability to variations in walking environments, as previously stated.

On the other hand, an obstacle walk test has been proposed as an irregular surface condition $[9,10]$. It is a useful test to evaluate avoiding a stumble that induces a fall. However, the participants can see the obstacles placed in test walkways before they begin to walk, and are therefore more likely to maintain stability.

There has been little research on the gait of elderly people on varied surfaces. Therefore, a soft surface, such as a mattress, is considered to be adequate for the gait analysis of elderly individuals because the change of plantar aspect when contacting the surface increases the risk of falling. When an elderly person walks on soft surfaces, the plantar aspect changes and they are required to control the sway of their body by using somatosensory input through plantar and postural reflexes. It is much more difficult for an individual to maintain their balance when walking on a softer surface compared to a normal walkway.

Considering a fall process, it will be important to examine the body's stability during walking in the above walkway condition. It was hypothesized that gait property on soft surfaces differs from that under normal conditions, and is related to different physical functions, adding that walking on soft surfaces reflects more the degree of fall risk and independence of daily living. If physical functions related to gait properties on both walkway conditions differ, it is necessary to review the exercise and physical functions to prevent falls.

This study aimed to analyze gait property by threedimensional motion analysis on soft and normal surfaces and to clarify the relationship between physical function and fall risk.

\section{METHODS}

\subsection{Participants}

Seven older men (Age: $72.4 \pm 5.2$ years, Height: 162.6 $\pm 6.2 \mathrm{~cm}$, Body mass: $65.7 \pm 13.0 \mathrm{~kg}$ ) and seventeen women (Age: $74.6 \pm 7.5$ years, Height: $148.9 \pm 7.3 \mathrm{~cm}$, Body mass: $52.2 \pm 9.8 \mathrm{~kg}$ ) living independently without any assistive devices in the community dwelling participated in this study. There was no significant difference in the mean ages of the sexes $(\mathrm{t}(22)=0.670, \mathrm{p}=0.510)$. Informed consent was obtained from each participant after a full explanation of the experimental project and its procedure. This study was approved by the Ethics Committee on Human Experimentation of Faculty of Educa- tion, Kanazawa University.

\subsection{Experimental Device}

For the three-dimensional kinematic gait analysis, sixteen passive markers (15-mm diameter reflective, adhesive styrofoam) were attached bilaterally to the following anatomic landmarkers; acromion, olecranon, ulnar head, anterior iliac crest, greater trochanter, knee, ankle and fifth metatarsal. Marker trajectories were recorded two strides after one stride from onset of walking at $60 \mathrm{~Hz}$ by six digital camcorders (MA-2000, Anima, Japan). Tridimensional reconstruction of the marker trajectories was performed by means of a reference system (leveling wires with equally spaced markers, forming a cube $3.0 \mathrm{~m}$ in length, $1.70 \mathrm{~m}$ in height, and $1.30 \mathrm{~m}$ in width) in order to calibrate the experimental set.

Gait parameters were selected as follows: mean walk velocity, standard deviations of the movement distance of joint points (acromion, knee, and ankle) in the frontal and sagittal directions [11]. Further analysis was performed on only the right joint points because the movement distance between the right and left joints had a 0.95 correlation.

\subsection{Procedure}

Using within-subjects design, the participants performed a 5-m walk at their own maximal speed on normal and soft surface walkways. The trial order on both walkway conditions was allocated randomly, and the rest among the trials was set 10 minutes. The participants walked on a low rebound urethane foam mattress (Blance mattress, Achiless, Japan; width: 970 mm, depth: 603 $\mathrm{mm}$, thickness: $80 \mathrm{~mm}$ ) spread on the soft surface walkway. The toughness of mattress was $75 \mathrm{~N}$ and the ratio of renaturation was $92 \%$.

\subsection{Falls Risk Assessment Score and Independent of Daily Living Score}

Fall risk was estimated using a fall risk assessment questionnaire [4-12]. This consisted of eight risk factors (gait deficit, balance deficit, muscle weakness, disease, medication use, environment, visual and hearing deficit, and fall fears: 15 items). Participants answered all questions with a dichotomous scale (yes or no). The response with a high risk category for each question was considered to be a "high-risk response", and persons scoring over five points were judged to have a high fall risk.

Independence of daily living was estimated from the view point of physical function level by falls efficacy scale [13] and activity of daily living (ADL) test [14]. The former consists of 13 items common to daily living, and participants were evaluated regarding their confidence with these items on a scale of one to ten. The ADL 
test consisted of 12 items representing ADL domains of walking ability, changing and holding posture, balance, and muscular strength and dexterity (manual activity).

\subsection{Tests of Leg Function}

Tests of leg function were selected from leg strength and dynamic balance ability which related to mobility/ transfer movement and posture control ability: isometric muscle strength tests of toe flexion, knee extension, and hip flexion joints in the former, and a functional reach test in the latter. Isometric muscle strength tests were performed twice for both legs using a hand held dynamometer ( $\mu$ TAS F-1, ANIMA, JAPAN). A mean of a higher value in both legs was used as maximal strength in each joint. Plantar flexion was measured in long sitting position, and the others were measured in sitting position. Functional reach was measured by using an elastic stick [15]. Each participant maximally extended the dominant hand from an upright posture while touching the top of an elastic stick fixed at dominant acromion height on the wall. They pushed and shortened the elastic stick by extending the dominant hand and the shortened distance of the elastic stick was measured.

\subsection{Data Analysis}

An unpaired t-test was used to reveal sex differences in the fall risk assessment score and independence of daily living score. Two-way ANOVA ( $\operatorname{sex} \times$ walkway condition) was use to reveal the difference of gait parameters between both surface conditions. Pearson's correlation coefficient was calculated to clarify the relationships between gait parameters under both walkway conditions, fall risk score, independence of daily living score, and leg function. A probability level of 0.05 was indicative of statistical significance.

\section{RESULTS}

Table 1 shows sex differences of fall risk scores, independence of daily living scores, and leg function. There were no significant sex differences in all parameters. All effect sizes by Cohen's d were less than moderate values $(\mathrm{d}<0.68)$.

Figure 1 shows exemplification of the gait pattern analyzed by joint point trajectories in the frontal and sagittal directions. The gait properties on a soft surface tended to swing up and down in each joint and to lean to the right and left directions significantly as compared with the normal surface. Moreover, it tended to decrease with a step length and to increase with step width.

Table 2 shows the result of two-way ANOVA ( $\operatorname{sex} \times$ walkway condition) regarding gait parameters. There were significant walkway condition effects in all parameters. Walk velocity on soft surface significantly de- creased, and body sway in the right-left and up-down directions significantly increased. Effect sizes between walkway conditions by sexes were over 0.5 in all parameters. In particular, the effect of the magnitude of the standard deviation of movement distance in the sagittal direction was relatively high $(1.2-5.2)$.

Table 3 shows the correlation coefficients among gait parameters, fall risk score, and independence of daily living score by sexes. Walk velocity on the soft surface correlated significantly with fall efficacy scale and ADL score in both sexes.

Table 4 shows the correlation coefficients between gait parameters and leg functions by sexes. All gait parameters, except for standard deviation of movement distance in frontal direction at acromion and knee in males, on soft surface correlated significantly with functional reach in both sexes. On the other hand, those on normal surfaces tended to correlate significantly with leg strength.

\section{DISCUSSION}

This study examined whether the gait properties and their relationship with the fall risk score and leg functions differ between those on the soft surface which changes the plantar aspect during foot contact and on the normal surface.

Takenaka and Uechi [16] reported that sex differences were not found in walking velocity and fall self-efficacy scale for people 61 - 91 years of age. In previous studies, the findings of sex difference on fall incidence were not always agreement. Some researchers reported that they were higher in women than in men $[4,17,18]$, but others reported that there was no significant difference $[19,20]$. Physical fitness level varies among individuals because it does not only relate to sex and aging, but also relates to various factors such as chronic disease, physical activity and cognition function. There were no significant sex differences in age, fall risk score, independence of daily living score, and leg strength in this study. The effect sizes by Cohen's $d$ in fall risk and ADL score, and leg strengths were moderate $(0.40-0.68)$, and the sex difference in these parameters will be found in studies with a larger sample size.

The standard deviations of movement distance in frontal and sagittal directions in this study evaluate the degree of a joint sway. Walking velocity and body stability on soft surface decrease because the walkway sinks down during foot contact. Body sway of acromion in the frontal direction on soft surface was larger than that of knee and ankle joints. It is inferred that walking on a soft surface causes an unanticipated inverted pendulum sway supporting a foot contact point because of the disturbance by the sagging walkway. That is, walking on the soft surface required to keep the body in balance. On the other hand, body sway in the sagittal direction was larger 
Table 1. Sex differences of fall risk score, independence of daily living score, and leg muscle functions.

\begin{tabular}{|c|c|c|c|c|c|c|c|}
\hline & & \multicolumn{2}{|c|}{ Male $(n=7)$} & \multicolumn{2}{|c|}{ Female $(\mathrm{n}=17)$} & \multirow{2}{*}{$\mathrm{t}$} & \multirow{2}{*}{ ES } \\
\hline & & M & $\mathrm{SD}$ & M & $\mathrm{SD}$ & & \\
\hline Fall risk score & point & 3.9 & 2.6 & 2.9 & 2.2 & 0.9 & 0.40 \\
\hline Fall efficacy scale & point & 122.1 & 12.3 & 122.5 & 10.4 & 0.1 & 0.04 \\
\hline ADL score & point & 29.7 & 4.6 & 26.6 & 6.0 & 1.2 & 0.55 \\
\hline Toe flexion strength & $\mathrm{kg}$ & 5.6 & 3.0 & 4.1 & 2.0 & 1.5 & 0.68 \\
\hline Knee extension strength & $\mathrm{kg}$ & 17.0 & 7.3 & 14.1 & 3.7 & 1.3 & 0.57 \\
\hline Hip Flexion strength & $\mathrm{kg}$ & 23.1 & 11.3 & 19.1 & 6.4 & 1.1 & 0.50 \\
\hline Functional reach & $\mathrm{cm}$ & 32.3 & 6.6 & 32.2 & 5.6 & 0.0 & 0.00 \\
\hline
\end{tabular}

There were no significant sex differences in any parameters.
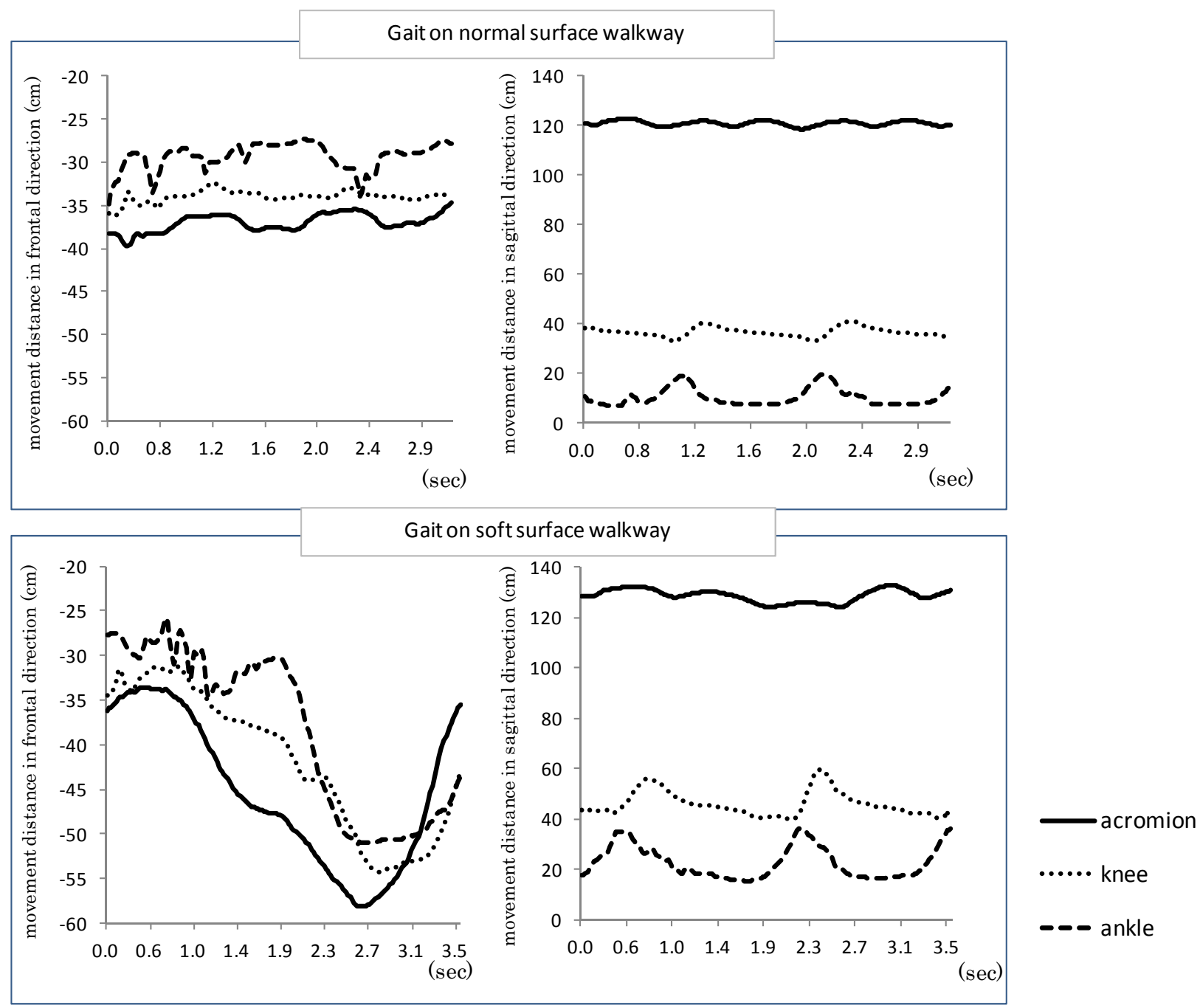

Figure 1. Exemplification of gait pattern analyzed by movement distance of 8 joint points (only right side) on the both surface conditions. Upper panel: normal surface walkway, Lower panel: soft surface walkway.

in the knee and ankle joints than in acromion. A sagging walkway by a foot contact makes the whole body sway to downward. However, body sway at acromion tended to be small as compared with that at knee and ankle joints. It is inferred that walking on soft surface required higher elevation of the foot during the swing phase. 
Table 2. Two-way ANOVA of gait parameters between the both walkway conditions by sexes.

\begin{tabular}{|c|c|c|c|c|c|c|c|c|c|c|c|c|c|}
\hline & \multicolumn{4}{|c|}{ Soft surface } & \multicolumn{4}{|c|}{ Normal surface } & \multirow{3}{*}{$\frac{\operatorname{sex}}{\mathrm{F}}$} & \multicolumn{2}{|c|}{ Two-way ANOVA } & \multicolumn{2}{|c|}{$\begin{array}{c}\text { Effect size } \\
\text { between both } \\
\text { walkway } \\
\text { conditions }\end{array}$} \\
\hline & \multicolumn{2}{|c|}{ Male } & \multicolumn{2}{|c|}{ Female } & \multicolumn{2}{|c|}{ Male } & \multicolumn{2}{|c|}{ Female } & & \multirow{2}{*}{$\begin{array}{c}\begin{array}{r}\text { walkway } \\
\text { condition }\end{array} \\
\text { F }\end{array}$} & \multirow{2}{*}{$\frac{\text { inter-action }}{\mathrm{F}}$} & \multirow[b]{2}{*}{ Male } & \multirow[b]{2}{*}{ Female } \\
\hline & M & SD & M & $\mathrm{SD}$ & M & SD & M & SD & & & & & \\
\hline $\begin{array}{c}\text { Walk } \\
\text { velocity } \\
(\mathrm{cm} / \mathrm{s})\end{array}$ & 67.3 & 18.1 & 72.0 & 19.6 & 93.5 & 17.8 & 90.4 & 38.5 & 0.0 & $11.0^{*}$ & 0.3 & 1.6 & 0.6 \\
\hline \multicolumn{14}{|c|}{$\begin{array}{c}\text { Standard deviation of movement distance in frontal } \\
\text { direction }(\mathrm{cm})\end{array}$} \\
\hline acromion & 4.1 & 1.9 & 3.4 & 1.7 & 2.6 & 0.7 & 2.1 & 0.8 & 2.3 & $14.8^{*}$ & 1.3 & 1.1 & 1.0 \\
\hline knee & 2.9 & 1.0 & 2.6 & 1.8 & 1.7 & 0.7 & 1.8 & 0.9 & 0.2 & $5.8^{*}$ & 0.2 & 1.5 & 0.6 \\
\hline ankle & 3.9 & 1.3 & 2.9 & 2.0 & 2.1 & 0.7 & 2.1 & 1.0 & 1.1 & $7.8^{*}$ & 1.2 & 1.8 & 0.5 \\
\hline \multicolumn{14}{|c|}{$\begin{array}{l}\text { Standard deviation of movement distance in sagittal } \\
\text { direction }(\mathrm{cm})\end{array}$} \\
\hline acromion & 1.9 & 0.5 & 1.7 & 0.7 & 1.3 & 0.4 & 1.0 & 0.2 & 1.7 & $14.7^{*}$ & 0.0 & 1.5 & 1.2 \\
\hline knee & 3.3 & 0.5 & 3.4 & 0.7 & 1.4 & 0.2 & 1.3 & 0.3 & 1.0 & $337.1^{*}$ & 2.2 & 5.2 & 4.2 \\
\hline ankle & 6.5 & 1.1 & 6.3 & 0.9 & 4.9 & 0.9 & 4.1 & 0.7 & 2.1 & $105.0^{*}$ & 1.8 & 1.8 & 2.8 \\
\hline
\end{tabular}

Table 3. Correlation coefficients among gait parameters, fall risk score, and independence of daily living score.

\begin{tabular}{|c|c|c|c|c|c|c|c|c|c|c|c|c|}
\hline & \multicolumn{6}{|c|}{ Male } & \multicolumn{6}{|c|}{ Female } \\
\hline & \multicolumn{3}{|c|}{ Soft surface } & \multicolumn{3}{|c|}{ Normal surface } & \multicolumn{3}{|c|}{ Soft surface } & \multicolumn{3}{|c|}{ Normal surface } \\
\hline & $\begin{array}{l}\text { Fall risk } \\
\text { score }\end{array}$ & $\begin{array}{l}\text { Fall efficacy } \\
\text { scale }\end{array}$ & $\mathrm{ADL}$ & $\begin{array}{c}\text { Fall risk } \\
\text { score }\end{array}$ & $\begin{array}{c}\text { Fall } \\
\text { efficacy } \\
\text { scale }\end{array}$ & $\mathrm{ADL}$ & $\begin{array}{l}\text { Fall risk } \\
\text { score }\end{array}$ & $\begin{array}{c}\text { Fall } \\
\text { efficacy } \\
\text { scale }\end{array}$ & $\mathrm{ADL}$ & $\begin{array}{l}\text { Fall risk } \\
\text { score }\end{array}$ & $\begin{array}{l}\text { Fall efficacy } \\
\text { scale }\end{array}$ & $\mathrm{ADL}$ \\
\hline $\begin{array}{c}\text { Walk } \\
\text { velocity } \\
(\mathrm{cm} / \mathrm{s})\end{array}$ & -0.43 & $0.78^{*}$ & $0.76^{*}$ & -0.13 & -0.09 & 0.24 & -0.33 & $-0.65^{*}$ & $0.58^{*}$ & 0.08 & 0.14 & 0.33 \\
\hline \multicolumn{13}{|c|}{$\begin{array}{l}\text { Standard deviation of movement distance in frontal } \\
\text { direction }(\mathrm{cm})\end{array}$} \\
\hline acromion & -0.16 & 0.13 & 0.51 & 0.40 & -0.45 & -0.43 & 0.19 & 0.16 & -0.16 & 0.07 & -0.34 & -0.35 \\
\hline knee & -0.27 & 0.16 & 0.49 & 0.22 & 0.02 & 0.12 & -0.26 & 0.21 & 0.02 & 0.01 & 0.03 & 0.02 \\
\hline ankle & -0.10 & 0.64 & 0.22 & -0.32 & -0.38 & 0.22 & 0.06 & 0.23 & 0.10 & -0.04 & 0.07 & -0.03 \\
\hline \multicolumn{13}{|c|}{$\begin{array}{c}\text { Standard deviation of movement distance in sagittal } \\
\text { direction }(\mathrm{cm})\end{array}$} \\
\hline acromion & 0.72 & -0.17 & -0.42 & 0.52 & 0.03 & 0.14 & -0.01 & 0.26 & -0.01 & 0.04 & 0.19 & $0.51^{*}$ \\
\hline knee & 0.74 & 0.14 & -0.39 & 0.19 & 0.34 & -0.11 & -0.21 & 0.19 & 0.08 & -0.35 & 0.40 & 0.13 \\
\hline ankle & 0.35 & -0.13 & 0.18 & 0.30 & 0.45 & 0.11 & -0.23 & $0.49^{*}$ & 0.41 & -0.43 & $0.65^{*}$ & $0.74^{*}$ \\
\hline
\end{tabular}

Moreover, all correlations of gait parameters between both walkways were not high. Thus, walking properties on both walkways may be affected by different physical functions.

Significant correlations were not found between gait parameters and fall risk score. However, the independence score of daily living correlated significantly with walking velocity on a soft surface in both sexes and the sagittal direction sway of the ankle joint on a normal surface in females. Nine participants in this study were identified to have a high fall risk by cut-off score (5 points) $(37.5 \%)$, and the others were lower than 3 points. Fall risk scores involve not only physical function such as walking ability, leg strength, and balance ability, but also the other factors such as medicine, environment, personality, visual and hearing problems, and fear of falling $[4,12]$. From the present results, gait parameters may reflect mainly physical function factors. Meanwhile, 
Table 4. Correlation coefficients between gait parameters and leg muscle functions.

\begin{tabular}{|c|c|c|c|c|c|c|c|c|c|c|c|c|c|c|c|c|}
\hline & \multicolumn{8}{|c|}{ Male } & \multicolumn{8}{|c|}{ Female } \\
\hline & \multicolumn{4}{|c|}{ Soft surface } & \multicolumn{4}{|c|}{ Normal surface } & \multicolumn{4}{|c|}{ Soft surface } & \multicolumn{4}{|c|}{ Normal surface } \\
\hline & $\begin{array}{c}\text { Toe } \\
\text { flexion }\end{array}$ & $\begin{array}{l}\text { Hip } \\
\text { flexion }\end{array}$ & $\begin{array}{c}\text { Knee } \\
\text { extension }\end{array}$ & $F R$ & $\begin{array}{c}\text { Toe } \\
\text { flexion }\end{array}$ & $\begin{array}{l}\text { Hip } \\
\text { flexion }\end{array}$ & $\begin{array}{c}\text { Knee } \\
\text { extension }\end{array}$ & $n$ FR & $\begin{array}{l}\text { Toe } \\
\text { flexion }\end{array}$ & $\begin{array}{l}\text { Hip } \\
\text { flexion }\end{array}$ & $\begin{array}{c}\text { Knee } \\
\text { extensiol }\end{array}$ & on $\mathrm{FR}$ & $\begin{array}{c}\text { Toe } \\
\text { flexion }\end{array}$ & $\begin{array}{l}\text { Hip } \\
\text { n flexion }\end{array}$ & $\begin{array}{c}\text { Knee } \\
\text { extensior }\end{array}$ & FR \\
\hline Walk velocity $(\mathrm{cm} / \mathrm{s})$ & 0.02 & 0.18 & 0.32 & $0.76^{*}$ & 0.54 & 0.73 & 0.59 & 0.69 & 0.42 & 0.02 & 0.05 & $0.49^{*}$ & $0.48^{*}$ & 0.26 & 0.07 & 0.35 \\
\hline \multicolumn{17}{|c|}{ Standard deviation of movement distance in frontal direction $(\mathrm{cm})$} \\
\hline acromion & -0.26 & -0.11 & 0.30 & -0.45 & 0.24 & 0.32 & 0.30 & 0.30 & -0.45 & -0.35 & -0.35 & $-0.64^{*}$ & 0.18 & -0.02 & -0.15 & 0.34 \\
\hline knee & -0.47 & -0.45 & -0.05 & -0.49 & 0.49 & $0.81^{*}$ & 0.72 & 0.23 & -0.31 & -0.13 & -0.05 & $-0.48^{*}$ & $0.49^{*}$ & -0.21 & -0.15 & 0.27 \\
\hline ankle & -0.52 & -0.39 & -0.20 & $-0.81^{*}$ & 0.35 & 0.53 & 0.48 & -0.12 & -0.26 & -0.02 & -0.06 & $-0.48^{*}$ & $0.49^{*}$ & -0.37 & -0.29 & 0.11 \\
\hline \multicolumn{17}{|c|}{ Standard deviation of movement distance in sagittal direction $(\mathrm{cm})$} \\
\hline acromion & -0.08 & 0.19 & 0.30 & $-0.76^{*}$ & 0.44 & $0.84^{*}$ & $0.83^{*}$ & 0.73 & -0.31 & -0.15 & -0.19 & $-0.50^{*}$ & $0.64^{*}$ & -0.12 & -0.20 & 0.17 \\
\hline knee & -0.07 & 0.14 & 0.13 & $-0.77^{*}$ & -0.11 & -0.41 & -0.37 & 0.22 & 0.15 & 0.18 & -0.22 & $-0.52^{*}$ & -0.37 & -0.07 & -0.22 & -0.50 \\
\hline ankle & -0.08 & 0.22 & 0.28 & $-0.78^{*}$ & 0.08 & 0.24 & 0.12 & 0.35 & 0.43 & 0.13 & -0.10 & $-0.50^{*}$ & $0.48^{*}$ & -0.06 & $0.48^{*}$ & 0.18 \\
\hline
\end{tabular}

${ }^{*} \mathrm{p}<0.05$, FR: functional reach.

the independence score of daily living was composed of item groups related closely to physical function factors $[16,21]$. Hence, it may have shown relationships with gait parameters on both surfaces. However, it is noted that the gait parameters with significant correlations differed between both walkway conditions. Potter et al. [21] reported that a relationship was found between Barthel ADL score and walking speed. However, this relationship depends largely on the physical fitness level of the older population. Because walking five meters on a normal surface was an easy task for the elderly in this study, it is hard to attribute individual differences in gait by their physical fitness level. Therefore, it may have shown a poor relationship with the independence score of daily living.

Conversely, because walking on soft surface poses high difficulty, a significant relationship with walking velocity may have been found. Means [9] and Means and O'Sullivan [22] reported that walking at a high difficulty level such as navigating an obstacle is superior in the improvement ratio of physical function to walking normally for older people living in community-dwelling. Therefore, walking on a soft surface walkway may be effective as exercise for fall prevention. In addition, those displaying greater ankle movements in the sagittal direction on a normal surface tended to have a higher independence score of daily living. Foot height during the swing phase decreases with age and physical function decline [23]. In this study, the ankle movement of the sagittal and frontal directions in the normal surface correlated with toe flexion strength in females, thus it may important to improve toe flexion strength for the inde- pendence of daily living. Moreover, gait parameters on the normal surface in females, as compared with that on the soft surface, correlated with leg strength. This suggests that the greater movement of joint points during normal walking is affected by leg strength. These results may mean that persons with superior leg strengths walk forcefully on a normal surface.

On the other hand, almost gait parameters on soft surfaces correlated with a functional reach test in both sexes. This test was proposed to evaluate dynamic balance for older people [24]. As stated above, walking on a soft surface which prolonged the swing phase (the one-leg support phase) requires better balance ability. Walking on a low rebound urethane foam mattress makes it difficult to kick the ground when beginning walking and to elevate a leg due to soft surface. In case of normal walking, forcefully kicking the ground contributes to gain rapid and forceful movement. However, forcefully kicking the ground on the soft surface is needed large balance ability. Because the ankle movement in the sagittal direction on a soft surface correlated positively with functional reach, persons with superior functional reach may be able to elevate foot during swing phase. In fall prevention exercise schools, it is recommended to improve iliopsoas and femoral muscles to avoid stumbling over an obstacle $[25,26]$. However, it will also be important to propose exercise to positively move the center gravity of the body. Such exercises include the functional reach action which helps to keep body stable while walking on an irregular surface.

Further studies will be examined to clarify motion properties using kinematic analysis of other fall trigger 
actions such as slips and missteps which require a stepping strategy.

\section{CONCLUSION}

In conclusion, gait properties on soft surfaces which change the plantar aspect during foot contact differ from those on a normal surface. Body sway of the acromion in the frontal direction on a soft surface is larger than that of knee and ankle joints. Walking on a soft surface may cause an unanticipated inverted pendulum sway supporting a foot contact point because of the disturbance by the sagging walkway. Gait on the soft surface requires balance ability (functional reach) rather than leg strength.

\section{REFERENCES}

[1] Lord, S.R. and Dayhew, J. (2001) Visual risk factors for falls in older people. Journal of American Geriatrics Society, 49, 508-515. doi:10.1046/j.1532-5415.2001.49107.x

[2] Eke-Okoro, S.T. (2000) A critical point for the onset of falls in the elderly. A pilot study. Gerontology, 46, 88-92. doi:10.1159/000022140

[3] Ferrandez, A.M., Pailhous, J. and Durup, M. (1990) Slowness in elderly gait. Experimental Aging Research, 16, 79-89. doi:10.1080/07340669008251531

[4] Suzuki, T. (2003) Epidemiology and implications of falling among the elderly. Nippon Ronen Igakkai Zasshi, 40, 85-94. doi:10.3143/geriatrics.40.85

[5] Van der Velde, N., Stricker, B.H., Pols, H.A. and van der Cammen, T.J. (2007) Withdrawal of fall-risk-increasing drugs in older persons: Effect on mobility test outcomes. Drugs and Aging, 24, 691-699. doi:10.2165/00002512-200724080-00006

[6] Graham, R.C., Smith, N.M. and White, C.M. (2005) The reliability and validity of the physiological cost index in healthy subjects while walking on 2 different tracks. Archives of Physical Medicine and Rehabilitation, 86, 20412046. doi:10.1016/j.apmr.2005.04.022

[7] Podsiadlo, D. and Richardson, S. (1991) The timed "Up \& Go": A test of basic functional mobility for frail elderly persons. Journal of American Geriatrics Society, 39, 142148.

[8] Gill, J., Allum, J.H., Carpenter, M.G., Held-Ziolkowska, M., Adkin, A.L., Honegger, F. and Pierchala K. (2001) Trunk sway measures of postural stability during clinical balance tests: Effects of age. The Journals of Gerontology: Series A, 56, M438-M447. doi:10.1093/gerona/56.7.M438

[9] Means, K.M. (1996) The obstacle course: A tool for the assessment of functional balance and mobility in the elderly. Journal of Rehabilitation Research and Development, 33, 413-429.

[10] Rubenstein, L.Z., Josephson, K.R., Trueblood, P.R., Yeung, K. and Harker, J.O. (1997) The reliability and validity of an obstacle course as a measure of gait and balance in older adults. Aging, 9, 127-135.

[11] Kerrigan, D.C., Lee, L.W., Nieto, T.J., Markman, J.D., Collins, J.J. and Riley, P.O. (2000) Kinetic alterations independent of walking speed in elderly fallers. Archives of Physical Medicine and Rehabilitation, 81, 730-735. doi:10.1016/S0003-9993(00)90101-1

[12] Suzuki, T. (2000) Questionnaire for falls assessment of elderly people and its application. Health Assessment Manual. Kosei Kagaku Kenkyusho, Tokyo, 142-163.

[13] Hellstrom, K. and Lindmark, B. (1999) Fear of falling in patients with stroke: A reliability study. Clinical Rehabilitation, 13, 509-517. doi:10.1191/026921599677784567

[14] Ministry of Education, Culture, Sports, Science and Technology (1999) Guideline for new physical fitness test. http://www.mext.go.jp/a_menu/sports/stamina/03040901. htm

[15] Demura, S. and Yamada, T. (2007) Simple and easy assessment of falling risk in the elderly by functional reach test using elastic stick. Tohoku Journal of Experimental Medicine, 213, 105-111. doi:10.1620/tjem.213.105

[16] Takenaka, K. and Uechi, H. (2002) Development of falling self-efficacy scale for elderly people: The reliability and validity. Japan Journal of Physical Education, Health and Sport Sciences, 47, 1-13.

[17] Yasumura, S., Haga, H., Nagai, H., Shibata, H., Iwasaki, K., Ogawa, Y., Ahiko, T., Ihara, K. and Sakihara, S. (1994) Risk factors for falls among the elderly living in a Japanese rural community. Nippon Koshu Eisei Zasshi, 41, 528-537.

[18] Campbell, A.J., Spears, G.F. and Borrie, M.J. (1990) Examination by logistic regression modelling of the variables which increase the relative risk of elderly women falling compared to elderly men. Journal of Clinical Epidemiology, 43, 1415-1420. doi:10.1016/0895-4356(90)90110-B

[19] Yasumura, S., Haga, H., Nagai, H., Suzuki, T., Amano, H. and Shibata, H. (1994) Rate of falls and the correlates among elderly people living in an urban community in Japan. Age Aging, 23, 323-327. doi:10.1093/ageing/23.4.323

[20] Yasumura, S., Haga, H., Nagai, H., Shibata, H., Iwasaki, K., Ogawa, Y., Ahiko, T. and Ihara, K. (1991) Incidence of and circumstances related to falls among the elderly in a Japanese community. Nippon Koshu Eisei Zasshi, 38, 735-742.

[21] Potter, J.M., Evans, A.L. and Duncan, G. (1995) Gait speed and activities of daily living function in geriatric patients. Archives of Physical Medicine and Rehabilitation, 76, 997-999. doi:10.1016/S0003-9993(95)81036-6

[22] Means, K.M. and O'Sullivan, P.S. (2000) Modifying a functional obstacle course to test balance and mobility in the community. Journal of Rehabilitation Research and Development, 37, 621-632.

[23] Shin, S. and Demura, S. (2011) Different step-over movement strategies for disturbance stimulations. Perceptual and Motor Skills, 113, 11-18. doi:10.2466/25.26.PMS.113.4.11-18

[24] Clark, S., Iltis, P.W., Anthony, C.J. and Toews, A. (2005) 
Comparison of older adult performance during the functional-reach and limits-of-stability tests. Journal of Aging and Physical Activity, 13, 266-275.

[25] Hageman, P.A. and Thomas, V.S. (2002) Gait performance in dementia: The effects of a 6-week resistance training program in an adult day-care setting. International Journal of Geriatric Psychiatry, 17, 329-334. doi:10.1002/gps.597

[26] Jensen, J., Nyberg, L., Rosendahl, E., Gustafson, Y. and Lundin-Olsson, L. (2004) Effects of a fall prevention program including exercise on mobility and falls in frail older people living in residential care facilities. Aging Clinical and Experimental Research, 16, 283-292. 